\title{
Letters
}

Website: bmj.com

Email: letters@bmj.com

\section{Prevention of type 2 diabetes}

\section{Health promotion helps no one}

EDITOR-Narayan et al suggest that we use clinical and community based strategies to prevent type 2 diabetes. ${ }^{1}$ Over three years our small practice in Glasgow worked very hard to encourage healthy eating and exercise among our 2000 patients. We referred many patients to an exercise scheme, had a dietitian working in the practice, and organised health groups who met on a weekly basis where dietitian and doctor would weigh, encourage, motivate, and educate patients. Within a year almost half of my personal workload became this health promoting clinical input. In the end almost all of these patients required a continuous personal input to maintain their weight loss, regular exercise, or healthy eating, and it simply became unsustainable. Our energies were removed, and soon they all returned to their normal states.

I learnt a lot from that time. I listened to them in the health groups talking about the pressures and problems they faced. In the end I realised that it is not patients who don't understand but we doctors who don't. For how we behave, what we eat, what opportunities we have to exercise, are all shaped by what confronts us in our environment. If our

\section{Advice to authors}

We prefer to receive all responses electronically, sent directly to our website. Processing your letter will be delayed unless it arrives in an electronic form.

We are now posting all direct submissions to our website within 24 hours of receipt and our intention is to post all other electronic submissions there as well. All responses will be eligible for publication in the paper journal.

Responses should be under 400 words and relate to articles published in the preceding month. They should include $\leqslant 5$ references, in the Vancouver style, including one to the BMJ article to which they relate. We welcome illustrations.

Please supply each author's current appointment and full address, and a phone or fax number or email address for the corresponding author. We ask authors to declare any competing interest. Please send a stamped addressed envelope if you would like to know whether your letter has been accepted or rejected.

Letters will be edited and may be shortened.

bmj.com

letters@bmj.com

BMJ VOLUME 32327 OCTOBER 2001 bmj.com environment is unhealthy then we are unhealthy. I also learnt that the poorer you are then the more you are adversely affected by your environment; the richer you are the more easily you can manipulate your environment to create a health advantage. This is called having lifestyle choices. The poor are simply stuck with their usual foul environment.

The prevention of obesity and type 2 diabetes is an environmental problem and not a medical one. Clinical and community based health promotion strategies would simply waste enormous amounts of limited resources and end up being demoralising for both medical workers and patients alike. A healthy population requires a healthy environment where all have the ability and opportunity to follow a healthy lifestyle.

Politicians have clung long and hard to the convenient concept of health promotion, which asserts that illness is primarily self inflicted. This is evil and redundant. We must strangle health promotion before it strangles us. It is not individuals who mus change their behaviour, but politicians who must change their policies.

Colin Guthrie general practitioner 1448 Dumbarton Road, Glasgow G14 9DW grey triker@hotmail.com

1 Narayan KMV, Bowman BA, Engelgau ME. Prevention of
type 2 diabetes. BMJ 2001;323:63-4. (14 July.)

Prevention needs to reduce obesogenic environments

EDIToR-The trial by Tuomilehto et al showing the efficacy of diet and physical activity interventions for preventing type 2 diabetes is important and gives cause for optimism. It highlights the opportunities to prevent (or at least delay) a chronic, costly disease by using an individual level, lifestyle based programme. But how effective can such a clinical approach to diabetes prevention be outside the research trial situation?

The results of a similar dietary trial published concurrently were a little more sobering. ${ }^{2}$ Once the "intervention" period finished, body weight increased, and any residual gains from improved glucose tolerance applied only to the participants who were the most adherent to the programme. The parting comments about the need for a broader approach to diabetes prevention by Narayan et al in their editorial on the issue warrant amplification.
The costs of medical treatment of diabetes are huge, but so are the costs of population screening and lifelong, intensive interventions for people at high risk. Our increasingly "obesogenic" environments are the driving forces for weight gain and diabetes. This is especially true for socioeconomic groups at the lower end of the range, who have fewer options for negotiating and manipulating their environments. The investment in sequencing the human genome, searching for magic bullet solutions, and testing clinical interventions is enormous.

The investment in sequencing the human genome, searching for long term, collaborative solutions, and testing environmental, policy, and community interventions is, at best, trivial. As with other behavioural epidemics-for example, smoking, injuries, or heart disease-we need to look beyond the "host" if the epidemic is to be contained. ${ }^{4}$ Until the obesogenic environments take centre stage in a broader public health approach, ${ }^{5}$ the prevalence of obesity and type 2 diabetes will continue to rise, especially in populations with a low income and in disadvantaged populations.

Boyd Swinburn professor of public health nutrition swinburn@deakin.edu.au

Garry Egger adjunct professor

Physical Activity and Nutrition Research Unit, School of Health Sciences, Deakin University, Burwood, Victoria 3125, Australia

1 Tuomilehto J, Lindstorm J, Eriksson JG, Valle TT, Hamalainein $\mathrm{H}$, Ilanne-Parikka, et al, for the Finnish Diabetes Prevention Study Group. Prevention of type 2 diabetes by changes in lifestyle among subjects with impaired glucose tolerance. NEngl J Med 2001;344:1343-50.

2 Swinburn BA, Metcalf PA, Ley SJ. Long term (5 year) effects of a reduced-fat diet intervention in individuals with glucose intolerance. Diabetes Care 2001;24:619-24.

3 Narayan KMV, Bowman BA, Engelgau ME. Prevention of Narayan KMV, Bowman BA, Engelgau ME. P
type 2 diabetes. BMJ 200 1;323:63-4. (14 July.)

4 Egger G, Swinburn BA. An "ecological" approach to the obesity pandemic. BMJ 1997;315:477-80.

5 Swinburn BA, Egger GJ, Raza F. Dissecting obesogenic environments: The development and application of a framework for identifying and prioritising environmental interventions for obesity. Prev Med 1999;29:563-70.

\section{Reanalysis of twin studies suggests that diabetes is mainly genetic}

EDITOR-Two twin studies of type 1 diabetes have reached opposite conclusions. In one, a population based cohort of Danish twins in which one or both cotwins had type 1 diabetes was studied for the presence of islet autoantibodies. ${ }^{1}$ High rates of autoantibody positivity were identified in twins with and without diabetes. Since positivity did not differ between the monozygotic and 
Numbers of discordant twins positive for certain antibodies divided by numbers of samples tested

\begin{tabular}{lccc} 
& $\begin{array}{c}\text { Glutamic } \\
\text { acid } \\
\text { Islet } \\
\text { autoantibodies } \\
\text { decarboxylase } \\
\text { antibodies }\end{array}$ & $\begin{array}{c}\text { IA-2/ICA512 } \\
\text { antibodies }\end{array}$ \\
\hline Monozygotic: & & & \\
\hline Denmark & $0 / 10$ & $1 / 10$ & $0 / 10$ \\
\hline USA & $13 / 52$ & $14 / 38$ & $6 / 42$ \\
\hline Dizygotic: & & & \\
\hline Denmark & $1 / 35$ & $2 / 35$ & $0 / 35$ \\
\hline USA & $2 / 28$ & $3 / 23$ & $1 / 23$ \\
\hline
\end{tabular}

dizygotic twins it was suggested that a shared intrauterine or early postnatal environment might be more important than genetic factors. The second study found that the prevalence of islet autoantibodies was lower in initially unaffected dizygotic twins than monozygotic twins and did not differ from that found in unaffected non-twin siblings. The authors concluded that islet autoimmunity is determined predominantly by genetic rather than environmental factors. ${ }^{2}$

These conflicting findings might be due to differences in study design, differences between the two populations, or differences between the assays. The design of the studies differed greatly: the Danish study was population based and cross sectional, while the American one was clinic based and longitudinal. The American study also contained many more monozygotic twin pairs. The Danish study included all twin pairs regardless of diabetes status, whereas the American study included only those initially discordant for diabetes and did not analyse samples drawn after the development of diabetes. Both studies were comparatively small.

To resolve differences due to assay performance we exchanged serum samples; blinded samples were measured for insulin autoantibodies and glutamic acid decarboxylase and IA-2/ICA512 antibodies. Samples from all the Danish cases were exchanged, and samples from 34 of 53 monozygotic twins and 16 of 30 dizygotic twins from the American series were also measured. The assays used and their performance in international workshops have been reported elsewhere. ${ }^{34}$

Concordance between the assays was good. Since several American samples were not available for testing in both laboratories, the American assay was used for the comparison shown in the table, using data already published. The analysis was restricted to samples collected from unaffected twins, since affected twins were not analysed in the American study. Tests for islet cell antibodies were not repeated for this comparison, but IA-2/ICA512 antibodies are reported here for the first time in the Danish cohort.

The prevalence of autoantibodies was much higher in American than Danish discordant monozygotic twins. The likely explanation is that 12 of 13 antibody positive American twins subsequently developed diabetes and would be expected to have had autoantibodies before diagnosis. These individuals were classified as nondiabetic in the American series but would have been classified as diabetic in the Danish series. In contrast, the prevalence of autoantibodies was similar in the two groups of dizygotic twins, and the prevalence of autoantibodies and glutamic acid decarboxylase antibodies in the Danish twins was considerably lower than that in the previous report. The original analyses for islet autoantibodies and glutamic acid decarboxylase antibodies were performed blind in different laboratories. We attribute the discrepancy to improvements in assay performance and standardisation.

Reanalysis of the Danish cohort still shows no difference in the prevalence of islet autoantibodies between monozygotic and dizygotic twins, but the prevalence in both groups is much lower than that reported previously. Other differences, such as the contrast between autoantibody positivity in the monozygotic twin groups, can be attributed to study design and sampling procedures. Reanalysis of the Danish cohort does not exclude the shared uterine environment hypothesis, but the observation from the American study that discordant twins are no more likely than singleton infants to carry islet autoantibodies favours the genetic view.

Edwin A M Gale professor

Edwin.Gale@bristol.ac.uk

Polly J Bingley senior lecturer

Diabetes/Metabolism, Southmead Hospital, Bristol BS10 5NB

\section{George S Eisenbarth professor}

Maria J Redondo postdoctoral fellow

Barbara Davis Center for Childhood Diabetes, University of Colorado Health Sciences Center, Denver, CL 80262, USA

Kirsten O Kyvik professor

Genetic Epidemiology Research Unit, Institute of Community Health, Odense University, DK-5000 Odense, Denmark

Jacob S Petersen head of islet discovery research Novo Nordisk, Novo Alle (1KO3), 2880 Bagsvaerd, Denmark

1 Petersen JS, Kyvik KO, Bingley PJ, Gale EAM, Green A, Dyrberg T, et al. Population based study of prevalence of islet cell autoantibodies in monozygotic and dizygotic Danish twin pairs wies in monozygotic and dizygotic Danish twin pairs with insulin-dependent diabetes. BMJ

2 Redondo MJ, Rewers M, Yu L, Garg S, Pilcher C, Elliott RB, et al. Genetic determination of islet cell autoimmunity in monozygotic twin, dizygotic twin, and non-twin siblings of patients with type 1 diabetes: prospective twin study. $B M$ 1999;318:698-702

3 Yu L, Robles D, Abiru N, Kaur P, Rewers M, Kelemen K, et al. Early expression of antiinsulin autoantibodies of humans and the NOD mouse: evidence for early determination of subsequent diabetes. Proc Natl Acad Sci USA 2000;97:1701-6

4 Bingley PJ, Williams AJK, Gale EAM. Optimized autoantibody-based risk assessment in family member Implications for future intervention trials. Diabetes Care 1999;22:1796-801.

\section{National screening programme for diabetic retinopathy}

Screening by optometrists is better than screening by fundus photography

EDITOR-We have concerns about the National Screening Committee's recommendations for a risk reduction programme for diabetic retinopathy, in which digital photography is the screening method of choice. The gold standard for fundus examination is slit lamp biomicroscopy performed by an experienced ophthalmologist; this is the standard on which treatment decisions are made. The same technique used by other trained professionals in a screening environment duplicates the gold standard.

Slit lamp biomicroscopy has advantages over fundus photography. It offers a stereoscopic view, thereby detecting diffuse macular oedema that is missed by photography. The entire post-equatorial retina can be examined with this technique, whereas even seven-field photography misses about 17\% of the retina. ${ }^{2}$

The technical failure rate of photography is high and has been reported to be $14.4 \%$, compared with only $2.2 \%$ for ophthalmoscopy in the same group. ${ }^{3}$ In our district the technical failure rate of slit lamp biomicroscopy is $0.2 \% .^{4}$ Over-reading by trained graders has been reported in studies of photographic screening. ${ }^{2}$ One study looked at the performance of retina specialists compared with a standardised reading centre and found an overall agreement of only $74 \%$, concluding that there was a significant discrepancy in concordance.

The main reason for choosing digital photography seems to be the ease of audit, with no need for repeat examinations. However, the high technical failure rate of photography means that more re-examinations will be needed with this technique; a 5-10\% re-examination rate for audit purposes in an ophthalmoscopic screening system compares favourably with a $15 \%$ re-examination rate because of technical failure in a photographic screening system. ${ }^{34}$

We also have concerns about the cost of the different screening systems. A new national training infrastructure will be needed to provide accredited training for photographic screeners, whereas integrating retinopathy screening skills into the training of optometrists would be fairly easy. Thus training and accreditation costs would be lower for screening by optometrists.

The main cost of this screening is the fee paid to the optometrists. The national committee estimates this at $£ 20$, but in our district it is $£ 15$. This alone would reduce the overall cost by $£ 60000$ a year for a programme that had 12000 primary screen events a year. Most optometrists already have the necessary equipment, and thus the cost of new equipment for screening would be unlikely to be great.

Somdutt Prasad consultant ophthalmologist sprasad@rcsed.ac.uk

Helen Swindlehurst research nurse

Louis G Clearkin consultant ophthalmologist Wirral Hospital NHS Trust, Upton, Wirral

CH49 5PE

1 Freudenstein U, Verne J. A national screening programme for diabetic retinopathy. $B M J$ 2001;323:4-5. (7 July.)

2 Kinyoun JL, Martin DC, Fujimoto WY, Leonetti DL. Ophthalmoscopy versus fundus photographs for detecting and grading diabetic retinopathy. Investigative Ophthalmology and Visual Science 1992;33:1888-93.

3 Harding SP, Broadbent DM, Neoh C, White MC, Vora J Sensitivity and specificity of photography and direct ophthalmoscopy in screening for sight hy and direct ophthalmoscopy in screening for sight threatening eye disease. the Liverpool diabetic eye study. BMJ 1995;311: 
4 Prasad S, Kamath GG, Jones K, Clearkin LG, Phillips RP. Effectiveness of optometrist screening for diabetic retinopathy using slit lamp biomicroscopy. Eye (in press). 5 Gonzalez ME, Gonzalez C, Stern MP, Arredondo B, Martinez S. Concordance in diagnosis of diabetic retinopathy by fundus photography between retina pecialists and a standardized reading center. Mexico City Diabetes Study Retinopathy Group. Arch Med Res 1995;26:127-31

\section{Staff are already available to do this job}

EDITOR-Freudenstein and Verne advocate having trained non-medical staff to carry out retinal photography for diabetic retinopathy screening, but they fail to recognise the skills in the community that already exist-in optometric practices. ${ }^{1}$ As their editorial indicates, optometrists are already widely involved in local screening schemes, and increasingly this includes the use of retinal photography.

Schemes invariably operate in accordance with locally agreed protocols. National training recommendations were agreed some years ago by the Royal College of Ophthalmologists, the Royal College of General Practitioners, the College of Optometrists, and the (then) British Diabetic Association, and these are currently being updated to reflect modern technological practice.

The siting of digital cameras in community optometric practices provides accessibility and flexibility of appointment times for patients, rapid communication of screening results, and an opportunity for patient education. The use of slit lamp biomicroscopy and direct ophthalmoscopy in optometric practices allows refinement of referrals, and optometrists can detect coexisting disease and check for other ophthalmic conditions such as cataract, glaucoma, and anterior eye disease.

Why train and employ "screeners" when the staff are already available and can provide a wider range of skills?

Richard Broughton president

College of Optometrists, London WC2N 5NG hstanforth@college-optometrists.org

1 Freudenstein U, Verne J. National screening programme for diabetic retinopathy. BMJ 2001;323:4-5. (7 July.)

\section{Single definition of overweight and obesity should be used}

EDITOR-In May 2000 the BMJ published details of a new reference standard for childhood obesity developed by the International Obesity Task Force. ${ }^{1}$ The task force's standards take a logical and pragmatic approach to the problem of defining the cut-off points of body mass index indicating overweight and obesity in children.

In adults these cut-off points are based on the morbidity and mortality associated with excess weight. In the absence of such data in children the task force defined the cut-off points for young people by backextrapolating from the centile of body mass index corresponding to values of $>25$ $\mathrm{kg} / \mathrm{m}^{2}$ (overweight) and $30 \mathrm{~kg} / \mathrm{m}^{2}$ (obese) at age 18. Subsequent papers in the $B M J$ and elsewhere, however, have not all applied this definition, instead choosing more liberal cut-off points, usually the 85th and 95th centiles of national standards for overweight and obesity respectively. This practice has several flaws.

Firstly, different values are obtained according to which centile standards are used, which makes international comparisons impossible.

Secondly, the true nature of secular trends are obscured if updated standards are used; these standards are themselves affected by the developing epidemic of obesity (leading ultimately to the self fulfilling prophecy that there will always be $15 \%$ overweight and $5 \%$ obesity if these cutoff points are applied to contemporary standards).

Thirdly, the choice of 85th and 95th centiles effectively inflates the apparent number of overweight and obese children. ${ }^{2}$ This has led to confusion over the prevalence of obesity in young people.

The upward trend in childhood obesity is clearly of major concern even without any artificial inflation of the statistics. The prevalence of obesity has roughly trebled in 20 years ${ }^{4}$-a similar increase to that seen in adults. This secular trend should be the basis for strategies to tackle excess weight gain in young people. Exaggerating the absolute prevalence of obesity is ultimately unhelpful since it leads to confusing discrepancies in the transition from children to adults. For example, using the 95th centile of United Kingdom standards indicates that about $14 \%$ of 16 year olds were obese in the national diet and nutrition survey of young people $1997^{5}$; when the adult cut-off point of body mass index $30 \mathrm{~kg} / \mathrm{m}^{2}$ is used, however, only $5.8 \%$ are defined as obese.

Public health policy will best be served by a single definition of overweight and obesity in children and young people, which is consistently applied. We urge health professionals, scientists, and editors to adopt the International Obesity Task Force's proposed reference standard for obesity in children.

Susan A Jebb head of Nutrition and Health Research MRC Human Nutrition Research, Elsie Widdowson Laboratory, Cambridge CB1 9NL

Andrew M Prentice professor

MRC International Nutrition Group, London School of Hygiene and Tropical Medicine, London WC1B 3DP

1 Cole TJ, Bellizzi MC, Flegal KM, Dietz WH. Establishing a standard definition for child overweight and obesity worldwide: international survey. BMJ 2000;320:1240-3.

2 Rudolf MCJ, Sahota P, Barth JH, Walker J. Increasing prevalence of obesity in primary school children: cohor study. BMJ 2001;322:1094-5.

3 Bundred P, Kitchiner D, Buchan I. Prevalence of overweight and obese children between 1989 and 1998 population based series of cross sectional studies. BMJ 2001;322:1-4

4 Chinn S, Rona RJ. Prevalence and trends in overweight and obesity in three cross sectional studies of British children, 1974-94. BMJ 2001;322:24-6.

5 Finch S, Doyle W, Lowe C, Bates CJ, Prentice A, Smither $\mathrm{G}$, et al National diet and nutrition survey:people aged 65 years and over. Vol 1. Report of the of the diet and nutrition survey. London: Stationery Office, 1998.

\section{Predicting risk of death from cardiovascular disease}

\section{Which measurements are the most appropriate?}

EDITOR-I would like to predict the risk score for all patients in my practice aged 35 years or older as so clearly described in the article by Pocock et al. ${ }^{1}$ My enthusiasm invariably turns to disappointment when using risk scores because of the following six factors.

Age-Most of these studies stop at the age of 74 . As a significant proportion of my patients are aged 75 and over, I feel cheated. Is there any possibility of extrapolating the risk scores to an older age?

Smoking-Should I include former cigarette smokers who have only recently stopped smoking; recent being, for example, during the past year?

Blood pressure-Which measurement do I use? The most recent measurement, the average of the last three measurements, the highest recorded measurement, the average of the three highest recorded measurements, or a measurement with the patient seated, standing, or ambulatory, or the patient's own measurement?

Cholesterol concentration - Which measurement is the most appropriate? The most recent measurement, the average of the last three measurements, the highest recorded measurement, or the average of the three highest recorded measurements?

Creatinine concentration - Which measurement is the most appropriate? The most recent measurement, the average of the last three measurements, the highest recorded measurement, or the average of the three highest recorded measurements?

Left ventricular hypertrophy-How should it be defined? By evidence from echocardiography only, or by evidence from electrocardiography?

Ideally I would like to be able to discuss with a patient their current risk score and be able to compare with their previous risk scores, since when they have stopped smoking, blood pressure has been reduced, and their hypercholesterolaemia has been treated.

Likewise on a practice basis, I would like to be able to produce a "before and after" risk score to assess the effectiveness of the various treatments, which my practice has implemented often at great expense, time, and energy.

I am disappointed that the above points are not specifically addressed in this and other similar risk score assessments as to which are the most appropriate measurements of blood pressure, cholesterol, and creatinine concentrations to use to assess risk score.

Michael J White general practitioner

Stakes Lodge Surgery, Waterlooville PO7 8NS m.j.white@doctors.org.uk

1 Pocock SJ, McCormack V, Guevffier F, Boutitie F, Fagard $\mathrm{RH}$, Boissel JP. A score for prediction risk of death from cardiovascular disease in adults with raised blood pressure, cardiovascular disease in adults wh trased bressure, controlled trials. BMJ 2001:323:75-81. (14 July.) 


\section{Outcome prediction is hampered by methodological problems}

EDITOR-The paper of Pocock et al reports the detection of several risk factors of death in adults with raised blood pressure by the Cox proportional hazards model. ${ }^{1}$ The relation of the created new risk score to the probability of dying was clearly shown in the development set.

The paper is, however, flawed by the lack of validation in an independent sample of patients-a basic methodological principle of any predictive model. ${ }^{2}$ It would therefore be of utmost importance for Pocock et al to test the discrimination by receiver operator characteristic analysis and calibration of this suggested new risk model, especially when their calculations are based on older study populations, as pointed out by Vesti-Nielsen (electronic response published as letter below). ${ }^{3}$ An assessment of the usefulness of the model of Pocock et al will be possible only after this mandatory validation process.

Ville Pettilä senior consultant

Department of Anaesthesiology and Intensive Care Medicine, Helsinki University Hospital, 00029 HUS, Helsinki, Finland

ville.pettila@hus.f

1 Pocock SJ, McCormack V, Gueyffier F, Boutitie F, Fagard RH, Boissel JP. A score for prediction risk of death from cardiovascular disease in adults with raised blood pressure, based on individual patient data from randomised controlled trials. BMJ 2001;323:75-81. (14 July.)

2 Randolph AG, Guyatt GH, Calvin JE, Doig G, Richardson WS. Understanding articles describing clinical prediction tools. Evidence Based Medicine in Critical Care Group. Crit Care Med 1998;26:1603-12.

3 Ruttimann UE. Statistical approaches to development and validation of predictive instruments. Crit Care Clin validation of

\section{Individual cardiovascular risk cannot be predicted}

EDITOR-The article by Pocock et al is an interesting experiment in mathematics, but the authors cannot be serious when they suggest using this experiment for giving advice in the real world. ${ }^{1}$ If the rates for heart disease had been constant it would be useful in the real world instead of in the closed system of the article only, but they are not. Pocock et al mention the differing rates in different countries and admit that it would be difficult to predict a risk in, for example, France, on the basis of - as the calculations are-mainly old American and English studies.

But Pocock et al forget the even larger variations over time in many parts of the world. Cardiovascular mortality has been falling constantly at least since 1980, in most countries (except in the former Eastern bloc), by $2-7 \%$ yearly (for example, in the United Kingdom: Glasgow 2.6\%, Belfast 6\%; and in Sweden $3.8-8 \%$ in different centres per year). ${ }^{2}$

Two thirds of this reduction results from decreasing incidences of coronary heart disease. ${ }^{2}$ People are getting healthier. The calculations in the article have a built in blemish in that they are based on older studies in populations with substantially higher basic rates for cardiovascular disease. The logic in itself is flawless, but the arguments do not hold. It is impossible, on the basis of old studies, to predict in figures the absolute risk of cardiovascular death for a person living today, since the rates in the future are unknown, and whatever drives the changing rates is unknown as well. Perhaps the relative risks are the same, which I seriously doubt, but the absolute risks, necessary to advise a patient, have changed substantially.

Jörgen Vesti-Nielsen consultant physician Department of Medicine, Blenkingesjukhuset, 3748 Karlshamn, Sweden jorgen.vesti-nielsen@ltblekinge.se

1 Pocock SJ, McCormeck V, Gueyler F, Boutitie RH, Boissel JP. A score for prediction risk of death from ardiovascular disease in adults with raised of death from based on individual patient data from randomise ontrolled trials. BMJ 2001;323:75-81. (14 July.)

2 Tunstall-Pedoe H, Kuulasmaa K, Mähönen M, Tolonen H, Ruokoski E,Amouyl P. Contribution of trends in surviva and coronary-event rates to changes in coronary heart disease mortality: 10-year results from 37 WHO MONICA Project populations. Lancet 1999;353:1547-57.

\section{Authors' reply}

EDITOR-In reply to White, extrapolating risk scores to ages over 75 is desirable, but our data (like those of others) include few such elderly subjects. The benefits of stopping smoking are not immediate so recent former smokers may be counted as current smokers. Showing the reduction in risk, however, if counted as a non-smoker may help motivation.

For blood pressure, cholesterol and creatinine concentrations we would encourage use of averages of repeat recent measurements if available since this reduces withinsubject variation. Our study used at least three seated blood pressures. Evidence of left ventricular hypertrophy was provided by electrocardiogram..

Patients' changes in risk score are valuable, especially if efforts to reduce risk are happening. Do, however, emphasise comparison with others of the same age and sex (our figure 3), since the inevitable risk increase with age may otherwise disappoint.

We appreciate Pettilä's desire for independent validation, but in this instance it is unrealistic. One would need a new current large cohort of subjects, screened for all risk factors and followed up for five years. From which populations would they come, what inclusion criteria would apply, and how long can we wait for such validation?

It cannot realistically be done in time or with sufficient representativeness. As VestiNielsen points out, any risk score for predicting five year cardiovascular mortality is by definition based on old data. We could adopt the defeatist stance that we cannot predict the future, and a person's true risk is dependent on time and place (and countless other features). This negative attitude is not shared by thousands of people accessing our website (www.riskscore.org.uk) to quantify individual risk. We argue that our risk score is based on a large international database of high quality. The established nature of the risk factors we included and the large number of deaths observed mean we have a precise estimation of individual risk.

It would be naive to propose that the risk score and its consequent probability of cardiovascular death within five years give the true exact future risk for each individual.
But that is not really the point. Our risk score should be seen as a motivational tool that encourages assessment of a patient's overall risk rather than focusing on a single factor-for example, blood pressure. This has been achieved in a style that many primary care physicians and other health professionals are finding useful. Many people might prefer to have their own copy of our risk score program rather than accessing our website. If so, please email Mike Bennett (mike.bennett@lshtm.ac.uk), whom we thank for writing this program.

Stuart J Pocock professor stuart.pocock@1shtm.ac.uk

Valerie McCormack research fellow Department of Epidemiology and Population Health, London School of Hygiene and Tropical Medicine, London WC1E 7HT

Francois Gueyffier physician

Service de Pharmacologie Clinique, Faculté RTH Laennec, BP 8071-69376, Lyons cedex 08, France

Robert H Fagard professor

Hypertension and Cardiovascular Rehabilitation Unit, University of Leuven, UZ Gasthuisberg, B-3000 Leuven, Belgium

\section{Dietary fats and prevention of cardiovascular disease}

\section{Conclusion may have been underplayed}

EDITOR-The paper by Hooper et al may fulfil the Cochrane review criteria for a meta-analysis of clinical trials, but it does not provide a systematic review of the issues relating to dietary fat intake and the prevention of cardiovascular disease.

It is important to consider the overall appropriateness of each trial before its inclusion in a meta-analysis. Several of the trials included are small or of short duration. It is difficult to imagine how the risk of coronary heart disease that has accrued over a prolonged period may be reversed by dietary modification in less than two years. The diet and infarction trial (fat modification arm) contributed the greatest number of cardiovascular end points, yet there are at least two reasons why this trial was unlikely to show a beneficial effect. Limited dietary instruction was given, so there was little change in cholesterol concentrations. Since modification of fat quality produces a predictable average change in cholesterol, there was clearly limited compliance with dietary advice. Furthermore, the study was too short (two years) to have the expected reduction in clinical events and mortality.

The Veterans' Administration study, which contributed the second largest number of deaths, fulfilled the criteria for a good randomised, controlled, double blind clinical trial. But the experimental diet entailed a ratio of polyunsaturated to saturated fatty acids of 1.5 , far greater than would today be considered desirable. Such a diet would be expected to reduce cholesterol and coronary heart disease morbidity and mortality-as indeed it did, but perhaps not total mortality, as was also the case. Is it appropriate to compare such an intervention with that used in 
the Oslo study, in which saturated fats were replaced by whole grain cereals, vegetables, fruit, and some unsaturated fatty acids and in which study cardiovascular events and total mortality were reduced?

Meta-regression analyses were used to disentangle these issues, but one might question whether the statistical power was sufficient for this. One might also question why Hooper et al chose to examine total cardiovascular rather than coronary artery end points since there has never been any serious understanding that changing dietary fat does much to prevent strokes. The link is with coronary heart disease.

Finally, one might expect that in a systematic review the results of the trials would be interpreted in the context of the enormous body of descriptive epidemiology, which supports the link between dietary fat, cholesterol, and coronary heart disease. Although evidence based drug treatment now relies almost exclusively on clinical trials, when considering evidence based nutrition with links between nutrients and disease accumulating over a lifetime, it is imperative to consider epidemiological and experimental evidence in conjunction with trials.

It is nevertheless important to note the tentative conclusions offered by Hooper et al, when they say that there is a small but potentially important reduction in cardiovascular risk with reduction or modification of dietary fat intake, seen particularly in trials of longer duration. The conclusion seems to have been underplayed in the paragraph in This week in the $B M J$ that referred to this paper.

Jim Mann professor in human nutrition and medicine jim.mann@stonebow.otago.ac.nz

Murray Skeaff senior lecturer in human nutrition Department of Human Nutrition, University of Otago, Dunedin, New Zealand

Stewart Truswell professor of human nutrition Human Nutrition Unit, University of Sydney, Sydney, New South Wales 2006, Australia

Competing interests: The authors believe that there is no competing interest. However, the Department of Human Nutrition at the University of Otago has received some financial support and provision of products for research studies from a range of industries that might be regarded as being advantagedfor example, Unilever-or disadvantaged-for example, the New Zealand butter industry-by a reduction in saturated fatty acids in the population. ST has no competing interests.

1 Hooper L, Summerbell CD, Higgins JPT, Thompson R, Capps NE, Davey Smith G, et al. Dietary fat intake and prevention of cardiovascular disease: systematic review. $B M J$ 2001;322:757-63. (31 March.)

\section{Patient compliance should have been considered}

EDITOR-Despite its popular use in combining findings from multiple studies, metaanalysis has many pitfalls. ${ }^{1}$ These include lack of homogeneity of the studies, failure to consider important covariates, inadequate understanding of the scientific subject in question, failure to consider quality of the studies, and biases in including or excluding certain studies. Some of these pitfalls are exemplified in the paper by Hooper et al, who reviewed 27 intervention trials of fat reduction or modification.
There are several problems with this meta-analysis. Hooper et al mixed conceptually different approaches to dietary intervention-namely, total fat reduction versus using unsaturated fats to replace saturated fat. Neither epidemiology nor clinical trials support a benefit of low fat diets on either serum cholesterol or risk of coronary heart disease. Substitution of vegetable oils rich in unsaturated fats for saturated or trans fats, on the other hand, lowers low density lipoprotein and reduces cardiovascular end points, as indicated by several previous systematic reviews of this topic. A second problem is that the meta-analysis mixed studies specifically on cardiovascular disease with those designed for other purposes. It is questionable whether cardiovascular end points are adequately ascertained in those studies.

Hooper et al did not adequately consider compliance of the subjects. Poor compliance to a low fat diet is a well known problem in dietary trials. For example, the diet and infarction trial was unable to achieve anywhere close to the goal set for total fat. ${ }^{3}$ This and other trials showed minimal reduction in serum cholesterol with the dietary intervention, demonstrating poor adherence. In two earlier trials that showed cardiovascular benefits of unsaturated fats, adipose tissue fatty acid levels were used to monitor compliance. ${ }^{45}$ Although the Finnish mental hospital study was not included in the meta-analysis as it did not meet the subjective criteria, it did provide important evidence for an effect of fat modification. ${ }^{5}$

This meta-analysis highlights potential perils in combining oranges and apples in aggregating dietary studies. The included trials are a mix of aims, methods, populations, and quality. This same kind of approach was applied by one of the authors to cholesterol lowering drug trials. ${ }^{6}$ The results from that meta-analysis would predict that statins would increase mortality in the subsequent trials, whereas the opposite in fact occurred. Thus, a similar degree of caution is needed to interpret results from either a meta-analysis or an individual study.

Frank B Hu assistant professor

Frank Sacks professor

Walter C Willett professor

Department of Nutrition, Harvard School of Public Health, Boston, MA 02115, USA

Competing interests: None declared.

1 Bailar JC, 3rd. Passive smoking, coronary heart disease, and meta-analysis. N Engl J Med 1999;340:958-9.

2 Hooper L, Summerbell CD, Higgins JPT, Thompson R, Capps NE, Davey Smith G, et al. Dietary fat intake and preCapps NE, Davey Smith G, et al. Dietary fat intake and prevention of cardiovascular

2001;322:757-63. (31 March.)
Burr ML, Fehily AM, Gilbert JF, Rogers S, Holliday RM, 3 Burr ML, Fehily AM, Gilbert JF, Rogers S, Holliday RM,
Sweetnam PM, et al. Effects of changes in fat, fish, and fibre Sweetnam PM, et al. Effects of changes in fat, fish, and fibre
intakes on death and myocardial reinfarction: diet and intakes on death and myocardial reinfarction:
reinfarction trial (DART). Lancet 1989;2:757-61.

Dayton S, Pearce ML, Hashimoto S, Dixon WJ, Tomiyas U. A controlled clinical trial of a diet high in unsaturated fat in preventing complications of atherosclerosis. Circulation 1969;40(Suppl II):1-63.

5 Turpeinen O, Karvonen MJ, Pekkarinen M, Miettinen M, Elosuo R, Paavilainen E. Dietary prevention of coronary heart disease: The Finnish Mental Hospital Study Int J Epidemiol 1979.8:99-118.

Davey Smith G, Song F, Sheldon TA Cholesterol lowering and mortality: the importance of considering initial leve of risk. BMJ 1993;306:1367-73.

\section{Authors' reply}

EDITOR-Lowering or modifying dietary fat is associated, after two years, with a reduction in cardiovascular events (rate ratio $0.76,95 \%$ confidence interval 0.65 to 0.90 ). Mann et al suggest we were wrong to include short duration trials. Modification of dietary fat may have effects on coagulation pathways, and lipid lowering with a statin reduces C-reactive protein, ${ }^{1}$ both mechanisms by which more rapid effects might occur. Statins reduce stroke risk and raised blood concentrations of cholesterol are associated with increased risk of stroke, ${ }^{2}$ suggesting that it is sensible to examine cardiovascular (not simply coronary heart disease) end points.

$\mathrm{Hu}$ et al say that including fat lowering and fat modified diets is mixing apples with oranges, but both types of diet reduce low density lipoprotein cholesterol, ${ }^{3}$ and might therefore reduce cardiovascular events. There have not been enough trials providing adequate information in reports, making it impossible to obtain robust estimates of the separate effects of changes in total fat, saturated fat, or fat composition (for example, figure 1).

$\mathrm{Hu}$ et al criticise an earlier meta-analysis of fat lowering trials, saying that it would predict that statins would increase mortality in the Scandinavian simvastatin survival study (4S), WOSCOPS, LIPID, and CARE trials, whereas the opposite occurred. This is not the case. Meta-regression showed that greater cholesterol reduction resulted in larger reduction in mortality from coronary heart disease. Before statins, cholesterol reductions achieved were around 10\% rather than $20-25 \%$ seen with statins. Meta-regression predicts an odds ratio of 0.51 for deaths from coronary heart disease with simvastatin in the $4 \mathrm{~S}$ trial; the observed result was 0.58 .

The purpose of meta-analysis and metaregression is to provide a quantitative overview of current trial findings and highlight areas of uncertainty. The power of trials and meta-analyses of such trials over observational data is exemplified in the effect of vitamin $\mathrm{E}$ on coronary heart disease, where strong observational relations failed to be confirmed by meta-analysis of large-scale randomised controlled trials. ${ }^{4}$

Compliance is always a potential problem in dietary trials. We expected to see differential effects between trials providing advice and those giving food to participants. However, dietary advice trials appeared to have a similar effect on cardiovascular events (figure 5). The Finnish mental hospital study was not included as its design was non-randomised and therefore open to substantial bias, and consequently its exclusion was not subjective.

The consistent and strong graded relationships between serum cholesterol and coronary heart disease, and the rather weaker evidence linking dietary fat intake with coronary heart disease, is not disputed in terms of aetiology, nor is it challenged by our systematic review. We aimed to examine the effects of dietary intervention-the type of interventions that might be used in health promotion schemes or primary care. Over 
50 years of endeavour, dietary fat trials have amassed only 30000 patient years of observation in studies of at least 6 months duration, and only 8300 person years in trials of longer than two years. In comparison, the $4 \mathrm{~S}$ trial alone provided 19000 person years of observation, a mean of four years for each participant. Given the paucity of the data, it is remarkable that an effect of altering dietary fat was seen at all.

Lee Hooper research associate in evidence based care and systematic review

Manchester Dental and Education Centre (MANDEC), University Dental Hospital of Manchester, Manchester M15 6FH

lee.hooper@man.ac.uk

Carolyn D Summerbell reader in human nutrition School of Health, University of Teesside TS1 3BA

Rachel L Thompson senior research fellow in public health nutrition

Public Health Nutrition, Institute of Human Nutrition, Southampton General Hospital, Southampton SO16 6YD

Nigel E Capps consultant chemical pathologist for Shropshire

Department of Clinical Biochemistry

Princess Royal Hospital NHS Trust, Apley Castle, Telford TF6 6TF

George Davey Smith professor of clinical

epidemiology

Department of Social Medicine, University of Bristol, Bristol BS8 2PR

Rudolph A Riemersma senior lecturer in cardiac biochemistry

Cardiovascular Research, University of Edinburgh, Edinburgh EH8 9XF

Shah Ebrahim professor in epidemiology of ageing Department of Social Medicine, University of Bristol, Bristol BS8 2PR

Competing interests: None declared.

1 Ridker PM, Rifai N, Lowenthal SP. Rapid reduction in C-reactive protein with cerivastatin among 785 patients with primary hypercholesterolemia. Circulation 2001;103: 1191-3.

2 Wannamethee SG, Shaper AG, Ebrahim S. HDLcholesterol, total cholesterol and the risk of stroke in middle-aged British men. Stroke 2000;31:1882-8.

3 Clarke R, Frost C, Collins R, Appleby P, Peto R. Dietary lipids and blood cholesterol: quantitative meta-analysis of metabolic ward studies. BMJ 1997;314:112-7.

4 Hooper L, Ness A, Davey Smith G. Antioxidant strategy for cardiovascular disease. Lancet 2001,357:1705.

\section{Lifestyle, progesterone, and risk of breast cancer}

Causal association between progesterone concentrations and breast cancer has not been shown

EDITOR-Increasing progesterone concentrations are not associated with increasing incidence of breast cancer, despite the neat correlation diagram by Jasienska and Thune, and they are wrong to infer causality. ${ }^{1}$ Some points in their diagram are based on 20 or fewer samples, from which they draw conclusions about the whole country, and many of the progesterone values quoted do not coincide with their cited reference. ${ }^{2}$ However, the main criticism is that they have ignored other scientific data that do not reinforce their hypothesis.

In some places high progesterone concentrations have been found in conjunction with a low incidence of breast cancer-for example, Shanghai, where the progesterone concentrations of small numbers of Chinese women were similar or even higher than women in Chicago or Harvard..$^{3-5}$ This is despite the fact that the incidence of breast cancer is 19.1 per 100000 women with adjustment for age in Shanghai compared with about threefold in the United States. ${ }^{\text {w1 }}$ Determinations were not necessarily carried out by the same methods, which probably leads to some technical differences. Nevertheless, the values would not fit even close to the correlation by Jasienska and Thune. More importantly, if there were a causal association between high progesterone concentrations and cancer women with breast cancer should have higher progesterone concentrations than normal controls, but they do not. ${ }^{\text {w2 ws }}$

Far from being a cause of breast cancer, progesterone (in the form of norethisterone acetate, a synthetic progesterone used because of oral availability) was until recently a treatment for disseminated breast cancer. ${ }^{\mathrm{w}}$

Richard A Wiseman honorary senior lecturer Department of Epidemiology and Population Health, London School of Hygiene and Tropical Medicine, London WC1E 7HT rawiseman@hotmail.com

References w1-4 are available on bmi.com.

1 Jasienska G, Thune I. Lifestyle, hormones, and risk of breast cancer. BMJ 2001;322;586-7. (10 March.)

2 Vitzthum VJ, Ellison PT, Sukalich S, Caceres E, Spielvoge H. Does hypoxia impair ovarian function in Bolivia women indigenous to high altitude? High Altitude Med Bio $2000 ; 1 ; 39-49$

3 Wong YF, Mao K, Panesar NS, Loong EPL, Chang AMZ $\mathrm{Mi}, \mathrm{ZJ}$. Salivary estradiol and progesterone during the normal ovulatory menstrual cycle in Chinese women. Eur Obstet Gynecol and Rep Biol 1990;34;129-35.

4 Lu Y-C, Bentley GR, Gann PH, Hodges KR, Chatterton RT Salivary estradiol and progesterone levels in conception and nonconception cycles in women: evaluation of a new assay for salivary estradiol. Fertil Steril 1999;71;863-8

assay for salivary estradiol. Fertil Steril 1999;71;863-8.

Lipson SF, Ellison PT. Comparison of steroid profiles in thum $R$ occunception

\section{Authors' reply}

EDITOR-We documented a strong, positive relation between risk of breast cancer and mean progesterone concentrations in premenopausal women from five populations. We did not postulate a direct causal relation between progesterone concentration and risk of breast cancer, as asserted by Wiseman. However, data supporting a relation between "oestrogen plus progestagens" and breast cancer risk do exist, although the role of progesterone in the aetiology of breast cancer is more controversial than that of oestradiol.

Firstly, epithelial cells of the breast have the highest mitotic activity in the luteal phase of the menstrual cycle, when progesterone production peaks. ${ }^{2}$

Secondly, combined oestrogen plus progestogen replacement therapy increases risk of breast cancer to a greater extent than does replacement of oestrogens alone.

Thirdly, reduction in breast cancer risk among obese premenopausal women is most likely a result of frequent anovulatory cycles and impaired progesterone production. Thus, a causal link between progesterone and the risk of breast cancer is biologically plausi- ble. In our analyses, however, progesterone concentrations were used only as reliable indicators of ovarian activity, without suggesting the dominant role of progesterone in the aetiology of cancer.

An evaluation of the relation between circulating concentrations of progesterone and oestradiol and risk of breast cancer is difficult because of pronounced seasonal and within cycle variation in hormone concentrations. Ovarian steroid production is sensitive to changes in body weight, physical activity, and energy balance. For example, hard working peasant women had a $25 \%$ reduction in progesterone concentrations compared with women whose work was less intense. ${ }^{4}$ Such difficulties in measurements of hormones probably account for inconsistent results of studies testing the link of ovarian steroids to breast cancer.

Women from populations differing in lifestyle should differ in lifetime concentrations of ovarian steroids and, consequently, in rates of breast cancer. However, affluent women in any population are likely to have high concentrations of ovarian steroids, which may explain the recorded high concentrations of ovarian oestradiol and progesterone in the small sample of Shanghai women quoted by Wiseman. Such high concentrations may result from the excess of metabolic energy during development and adulthood. Since most urban, Western women have similar lifestyles, there is also low variation among them in concentrations of ovarian steroids. It would not be at all surprising if urban, premenopausal women with breast cancer did not differ from healthy women in concentrations of oestradiol and progesterone.

In addition, the time lag from the age of exposure to the age of diagnosis of breast cancer is considerable. Therefore, steroid concentrations measured around the time of diagnosis may not reflect the concentrations present during the critical period of cancer development.

Grazyna Jasienska assistant professor, reproductive biology

Institute of Public Health, Jagiellonian University, 31-531 Kraków, Poland

jasienska@post.harvard.edu

Inger Thune associate professor, cancer epidemiology Institute of Community Medicine, Norwegian Cancer Society, Faculty of Medicine, University of Tromso, 90037 Tromso, Norway

A longer version of this letter with complete references is available on bmj.com

1 Key TJA, Pike MC. The role of oestrogens and progestagens in the epidemiology and prevention of breast cancer. Eur J Clin Oncol 1988:24:29-43.

2 Kaacks R. Endogenous hormone metabolism as an exposure in breast cancer chemoprevention studies. In: Mille AB, Bartsch H, Dragsted P, Vainio H, eds. Biomarkers in cancer chemoprevention. Lyons: IARC Scientific Publications, 2001:149-62.

3 Ross RK, Paganini-Hill A, Wan PC, Pike MC. Effect of hormone replacement therapy on breast cancer risk: Estrogen versus estrogen plus progestin. J Nat Cancer Inst 2000;92:328-32

4 Jasienska G, and Ellison PT. Physical work causes suppression of ovarian function in women. Proc $R$ Soc Lond B 1998;265:1847-51.

5 Bernstein L, Yuan JM, Ross RK, Pike MC, Hanisch R, Lobo $\mathrm{R}$, et al. Serum hormone levels in pre-menopausal Chinese women in Shanghai and white women in Los Anines: wosults from two breast concer case-control studies. Causes Contr 1990;1:51-8. 


\section{Study shows that smoking costs 13 times more than it saves}

EDITOR-Kmietowicz's news article discussed the report published by the tobacco company Philip Morris which many media reports have claimed shows that smoking saves the economy more than it costs. ${ }^{1}$ A closer look shows the exact opposite: the report gives costs associated with smokers while still alive amount to Czech koruny (CZK) 15.7bn (\$517bn; £345bn) (on health care, absenteeism, fires, etc). These are some 13 times greater than CZK1.2bn "benefits" as a result of the early death of smokers (from savings on pensions, health care, housing, etc).

The study concludes that smoking is a net benefit, but only because it counts tobacco tax revenue of CZK20.3bn as a benefit. This is flawed economics: taxes are just a recycling of money in the economy. If there was no smoking in the Czech Republic, consumers would be spending their money on other things (which would also be taxed), and the government would be raising the budget it needs through other taxes, with no change in the total tax burden. The main difference would be a huge reduction in the burden of healthcare costs. Taxes just cannot be counted as a benefit in the same way that healthcare costs or savings can be counted.

Most criticism of the report has focused on the repellent concept of regarding early death as an economic benefit. But the report itself shows that even using its inhuman economic approach, smoking costs many times as much as any savings it might generate from killing off the recently retired.

Clive Bates director

Action on Smoking and Health, London EC2 4HW clive.bates@dial.pipex.com 1 Kmietowicz Z. Tobacco company claims that smokers help
the economy. BMJ 2001;32:126. (21 July.)

\section{Glucosamine for osteoarthritis}

\section{Patients' welfare should be primary concern}

EDITOR-Chard and Dieppe discussed the use of glucosamine in treating osteoarthritis. ${ }^{1}$ Osteoarthritis is traditionally treated with non-steroidal anti-inflammatory drugs and analgesics, just masking symptoms but doing nothing to improve the disease. Worst of all, non-steroidal anti-inflammatory drugs alone cause over 16500 deaths and over 103000 admissions to hospital each year in the United States. ${ }^{2}$

With regard to evidence based medicine, the authors of the Cochrane review on non-steroidal anti-inflammatory drugs for osteoarthritis of the knee conclude that, despite the large number of publications in this area, there are few randomised controlled trials. ${ }^{3}$ Furthermore, most trials comparing two or more such drugs have substantial design errors. The reviewers conclude that no substantial evidence is available related to efficacy, to distinguish between equivalent recommended doses of non-steroidal anti- inflammatory drugs. Had studies used appropriate doses of the drug that was being compared, most would have been sufficiently powerful to detect clinically important differences in efficacy. As differences in efficacy between non-steroidal anti-inflammatory drugs have not been recorded, the prescription of such a drug for osteoarthritis of the knee should be based on relative safety, acceptability to the patient, and cost.

A Cochrane review on glucosamine gave the following main results. ${ }^{4}$ Collectively, the reviewers identified 16 randomised controlled trials that provided evidence that glucosamine is both effective and safe in patients with osteoarthritis. In the 13 randomised controlled trials in which glucosamine was compared with placebo, glucosamine was found to be superior in al but one. In the four randomised controlled trials in which glucosamine was compared with a non-steroidal anti-inflammatory drug, glucosamine was superior in two and equivalent in two.

Additionally, new evidence was reported in a clinical trial published in January 2001, which showed that glucosamine sulphate can beneficially modify the disease process of osteoarthritis, from the point of view of both symptoms and structure. ${ }^{5}$ These results have already been confirmed in an independent trial, presented in November 2000 at the 64th annual meeting of the American College of Rheumatology in Philadelphia.

Glucosamine is currently the only substance known that can both help with the symptoms of osteoarthritis and improve the course of the disease, without showing any harmful effect for the patient. Despite its supplement status in certain countries, the evidence tells us that glucosamine must be taken seriously.

Davide Sonnino

Medical Department, Rottapharm Italy, I-20052 Monza, Italy

Competing interests: DS works in the medical department of Rottapharm Italy, manufacturers of glucosamine sulphate

1 Chard J, Dieppe P. Glucosamine for osteoarthritis: magic, hype, or confusion? BMJ 2001;322:1439-40. (16 June.)

2 Wolfe MM, Lichtenstein DR, Singh G. Gastrointestinal toxicity of nonsteroidal antiinflammatory drugs. New Engl Med 1999;340:1888-99.

Watson MC, Brookes ST, Kirwan JR, Faulkner A. Non-aspirin, non-steroidal anti-inflammatory drugs for treating osteoarthritis of the knee (Cochrane review). Cochrane library. Issue 2 Oxford: Update Software 2001. Cocha hibrary. Issue 2. Oxford. Update Software, 2001. Towheed TE, Anastassiades TP, Shea B, Houpt J, Welch V, Hochberg MC. Glucosamine therapy for treating osteoarthritis (Cochrane review): In: Cochrane Library. Issue 2.
Oxford: Update Software, 2001.

5 Reginster JY, Deroisy R, Rovati LC, Lee RL, Lejeune E, Bruyere $\mathrm{O}$, et al. Long-term effects of glucosamine sulphate on osteoarthritis progression: a randomized, placebo-controlled clinical trial. Lancet 2001;357:251-6.

\section{Sound science might have helped avoid confusion}

EdiToR-In their editorial Chard and Dieppe are right to conclude that there is more confusion and hype than magic about glucosamine. ${ }^{1}$ The confusion is largely the result of poor knowledge of the chemical, pharmacokinetic, and therapeutic properties of glucosamine. The editorial itself is biased by several examples of this confusion.
Firstly, glucosamine is not a sulphated (ester with sulphuric acid) aminomonosaccharide, as defined in the editorial. There is confusion with the sulphated disaccharide units of some glycosaminoglycans such as chondroitin sulphate.

Secondly, whether these large molecules can reach chondrocytes in vivo by the oral route is unclear. For glucosamine the preferential uptake by articular cartilage after oral administration is proved. ${ }^{2}{ }^{3}$

Thirdly, their statement is strange that osteoarthritic cartilage should not be cured because it has no nerve endings and is therefore not the origin of pain. Have Chard and Dieppe never heard about cytokines released from damaged tissues that produce pain and inflammation?

Fourthly, the statement that the most appropriate dose and route of administration is still unknown is outdated. The efficacy of glucosamine sulphate in daily oral doses of $1500 \mathrm{mg}$ on the symptoms of osteoarthritis is documented by several clinical trials and recently by two three year studies, in which a structure modifying effect was also shown. ${ }^{4}$

Fifthly, Chard and Dieppe do not know how to classify glucosamine-is it a drug, a food supplement, a nutriceutical, or a complementary treatment? Glucosamine is classified in one or another of the mentioned categories in different countries according to the local regulations. All pivotal clinical trials were made with glucosamine sulphate regulated as a drug. In several countries, including the United Kingdom and the United States, glucosamine as its sulphate or hydrochloride is freely available also as a food supplement. As such it is not subject to control for quality and for promotional claims, especially the kind found in the lay press.

As scientists, Chard and Dieppe should have been able to discern the therapeutic merits of glucosamine on the basis of scientific evidence from the hype of unregulated non-medical fantastic promotion. An editorial based on sound and unbiased chemical, pharmacokinetic, and clinical knowledge would have surely contributed to dispelling much of the confusion about glucosamine. Unfortunately this was not the case.

Ivo Setnikar scientific director

Rotta Research Laboratorium, I-20052 Monza, Italy ivo.setnikar@rotta com

Competing interest: IS is scientific director of Rotta Research Laboratorium; Rottapharm Italy manufacures glucosamine sulphate.

1 Chard J, Dieppe P. Glucosamine for osteoarthritis: magic, hype, or confusion? BMJ 2001;322:1439-40. (16 June.) 2 Setnikar I, Giachetti C, Zanolo G. Pharmacokinetics of glucosamine in the dog and in man. Arzneim-Forsch 1986;36: $729-35$.

3 Dodge GR, Regatte RR, Hall JO, Borthhakur A, Sarme A, Callaway DA, et al. The fate of oral glucosamine traced by ${ }^{13} \mathrm{C}$-labeling in the dog. Abstract. Meeting of the American College of Rheumatology, San Francisco, November 2001. 4 Reginster JY, Deroisy R, Rovati LC, Lee RL, Lejeune E, Bruyere $\mathrm{O}$, et al. Long-term effects of glucosamine sulphate on osteoarthritis progression: a randomized, placebo-controlled clinical trial. Lancet 2001;357:251-6.

5 Pavelka K, Gatterova J, Olejarova M, Machacek S, Giacovelli G, Rovati LC. A long-term, randomized, placebo-controlled, confirmatory trial on the effects of placebo-controlled, confirmatory trial on the effects of gluArthritis Rheum 2000:43:9(S1908). 


\section{Authors' reply}

EDITOR-We are pleased to respond to two of the 16 rapid responses posted on bmj.com in response to our editorial on glucosamine as their authors make some valid points.

Sonnino compares the Cochrane reviews on how harmful non-steroidal antiinflammatory drugs can be and how effective glucosamine is. This may be true, but it does not relate to the main thrust of our editorial. We have never denied that the published evidence suggests that glucosamine works, although we (like the Cochrane reviewers) did point out the need for larger studies. Our main point is that commercial biases and publication biases, for example, might affect the validity of these data. These are not issues covered by Cochrane reviews, which only report on the quality of published evidence. Finally, we, like Sonnino, reported that a recently published trial indicated that glucosamine might have an effect in modifying the structure, although we urge caution in the interpretation of these data as there are unresolved methodological issues surrounding the use of radiographic measures of joint space narrowing.

Setnikar raises five issues.

Firstly, glucosamine is not sulphated. This is correct, and we apologise for adding to the confusion about this.

Secondly, oral doses do reach the chondrocytes-again we accept that there is some evidence to support this view.

Thirdly, he takes issue with our suggestion that cartilage might play little part in pain generation in osteoarthritis. But we maintain that, although this might theoretically be possible, there is no direct evidence for cartilage involvement; what little evidence there is on the source of pain in osteoarthritis would favour bone. ${ }^{3}$

Fourthly, Setnikar maintains that $1500 \mathrm{mg}$ daily is the established optimum dose. We agree that this is the standard dose mentioned in the literature, but we were unable to identify any dose-response studies published, in English, on which this figure was based, and trials by Hughes et al and Houpt et al show that glucosamine is not effective at $1500 \mathrm{mg}$ daily. ${ }^{5}$

Finally, he raises an important point about avoiding media hype in medicine and basing recommendations on valid scientific evidence. We agree-in our editorial we included only trials and reviews, ignoring the multitude of comments that promote the use of glucosamine. We also highlighted the fact that the number of comments, reviews, letters, and editorials will soon overtake the amount of primary evidence.

Jiri Chard research associate

Paul Dieppe director

Medical Research Council Health Services Research Collaboration, Department of Social Medicine, University of Bristol, Bristol BS8 2PR Competing interests: None declared.

1 Electronic responses. Glucosamine for osteoarthritis. bmj.com 2001;322 (www.bmj.com/cgi/eletters/322 7300/1439; accessed 17 Oct 2001).

2 Mazzuca SA, Brandt KD, Dieppe PA, Doherty M, Sowers MF, Katz BP, Lane KA. Effect of radioanatomic position of the osteoarthritic $(\mathrm{OA})$ knee on joint space narrowing the osteoarthritic (OA) knee on joint space narrowing (JSN) in conventional standing extend
Arthritis Rheum 2000;43:926 (suppl. S).
3 Dieppe P. Subchondral bone should be the main target for the treatment of pain and disease progression i osteoarthritis. Osteoarthritis and Cartilage 1999;7:325-6.

4 Hughes RA, Carr AJ. A randomised, double-blind, placebo-controlled trial of glucosamine to control pain i osteoarthritis of the knee. Arthritis Rheum 2000;43:1903.

5 Houpt JB, McMillan R, Wein C, Paget-Dellio SD. Effect of glucosamine hydrochloride in the treatment of pain of osteoarthritis of the knee. J Rheumatol 1999:26:2423-30.

\section{Radiotherapy units should be seen as shared resource in EU}

EDITOR-In his news item on the ruling of the European Court of Justice in Luxemburg Watson cites the cases of a Belgian and two Dutch citizens in which refusal to sanction treatment in another member state of the European Union (EU) was judged unlawful. ${ }^{1}$ On this basis the plaintiffs covered by social insurance were eligible to have their costs reimbursed by the country that denied them treatment

How this ruling would apply to British patients waiting in excess of recommended maximum times for radiotherapy for cancer and seeking reimbursement for treatment in another member state of the European Union is not clear. Currently many British patients with cancer are waiting in excess of the maximum recommended by the Joint Council for Clinical Oncology: four weeks for curative (radical) radiotherapy and two weeks for palliative treatment. ${ }^{2}$ This is because of shortages of radiotherapy treatment machines (linear accelerators) or of the radiographers to deliver radiotherapy, or both. Delays in instituting radical radiotherapy for some cancers-for example, lung cancer ${ }^{3}$ - adversely affect survival.

Currently some patients in parts of southern Britain wait for up to 16 weeks for radiotherapy. The commitment in the national cancer plan for England, and its more recent equivalent in Scotland, to invest in new linear accelerators and appropriate staffing, is welcome. ${ }^{4}$ Even if all the necessary equipment could be purchased, there are real concerns that there will be insufficient trained radiographers to operate them to the necessary capacity.

Some members of the European Unionfor example, the Netherlands and Germanyalready have formal arrangements for crossborder referrals for radiotherapy. Perhaps the United Kingdom needs to look for a similar arrangement until it has adequate radiotherapy machines and staffing. For example, the number of linear accelerators in France per million of population is significantly higher (8.2) than that in England (3.8) and Scotland (3.0). ${ }^{5}$ There may be merit in agreeing with the French government and other neighbouring member states that the NHS will reimburse the costs of treating patients if the wait for radiotherapy treatment in the United Kingdom exceeds national guidelines.

Perhaps it is time to look on radiotherapy facilities in the European Union as a common resource to be maximised for the benefit of patients in member states. If not, individual patients may seek reimbursement from their health authorities for their cancer treatment in neighbouring states, seeking redress, if refused, through the European Court of Justice.

Ian Kunkler senior lecturer in clinical oncology University Department of Clinical Oncology, Western General Hospital, Edinburgh EH4 2XU I.Kunkler@ed.ac.uk

1 Watson R. European courts ruling paves way for cros border treatment. $B M J$ 2001;323:128. (21 July)

2 Joint Council for Clinical Oncology. Reducing delays in can cer treatment: some targets. London: Royal College of Physicians, 1993.

3 O'Rourke N, Edwards R. Lung cancer treatment waiting times and tumour growth. Clin Oncol 2000;12:141-4.

Department of Health. The NHS cancer plan: a plan for investment, a plan for reform. London: $\mathrm{DoH}, 2000$.

5 Scottish Executive. Cancer scenarios: an aid to planning cancer services in Scotland in the next decade. Edionbs: Scotish

\section{Open letter: health professions on the aftermath of terrorism}

EDITOR-We unreservedly condemn the attacks on New York and Washington, DC, on 11 September. We extend our heartfelt sympathy to the relatives, friends, and colleagues of the victims.

We are concerned that all responses should take account of the magnitude and complexity of the problem of combating terrorism of all kinds and its causes.

By virtue of their skills and experience, health professionals should take part in formulating appropriate responses to humanitarian needs in this crisis, taking into account lessons learnt from the past. In the longer term, building local capacity in the healthcare systems of affected populations will be an important contribution.

There is an urgent need to monitor the health of the population of Afghanistan and to make this information widely known and acted on in a way appropriate to the people of that country.

In the aftermath of the attacks social tension is increasing. We call on health professionals to help combat racism wherever encountered in health services and promote tolerance.

In the longer term we urge that in formulating foreign policy, governments should assess the effects of their proposed actions on the health and human rights of their own people and those likely to be affected in the wider world.

George Alberti president

Royal College of Physicians of London, London NW1 4LE

Sian Griffiths president

Faculty of Public Health Medicine of the Royal College of Physicians, London NW1 4LB

David Hall president

Royal College of Paediatrics and Child Health, London NW1 4LB

Roswyn Hakesley-Brown president

Royal College of Nursing, London W1M 0AB

John Cox president

Royal College of Psychiatrists, London SW1X 8PG

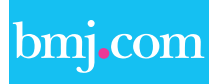

\section{Rapid responses}

Correspondence submitted electronically

is available on our website 